\title{
Youth gender differences in alcohol use: A prospective study of multiple youth assets and the neighborhood environment
}

\author{
Roy F. Oman ${ }^{1 *}$, Eleni L. Tolma ${ }^{1}$, Sara K. Vesely ${ }^{2}$, Cheryl B. Aspy ${ }^{3}$ \\ ${ }^{1}$ Department of Health Promotion Sciences, University of Oklahoma Health Sciences Center, Oklahoma City, USA; \\ *Corresponding Author: Roy-Oman@ouhsc.edu \\ ${ }^{2}$ Department of Biostatistics and Epidemiology, University of Oklahoma Health Sciences Center, Oklahoma City, USA \\ ${ }^{3}$ Department of Family and Preventive Medicine, University of Oklahoma Health Sciences Center, Oklahoma City, USA
}

Received 14 January 2013; revised 13 March 2013; accepted 12 April 2013

Copyright (C) 2013 Roy F. Oman et al. This is an open access article distributed under the Creative Commons Attribution License, which permits unrestricted use, distribution, and reproduction in any medium, provided the original work is properly cited.

\begin{abstract}
Research has identified factors (assets) that protect youth from engaging in risk behaviors including alcohol use. Very little research has examined asset/nonuse of alcohol associations by youth gender or determined if asset/nonuse of alcohol associations are influenced by the neighborhood environment. The purpose of the study was to determine if multiple youth assets and neighborhood factors are differentially associated with youth nonuse of alcohol by gender. Method: Five waves of data were collected annually from households $(\mathrm{N}=1111)$ randomly selected to participate in the Youth Asset Study. Seventeen assets and 6 neighborhood factors assessed at waves 1 - 4 were analyzed longitudinally using marginal logistic regression to predict nonuse of alcohol at waves 2 - 5. Results: Sample mean age was 14.3 years, $52 \%$ female; $39 \%$ white, $28 \%$ Hispanic, 23\% African-American, and $9 \%$ other. Numerous assets were prospectively associated with alcohol nonuse for females (12 assets) and males (16 assets). Three assets were significantly more protective from alcohol use for males compared to females. Final modeling indicated that three assets were protective from alcohol use for both genders and that one asset was protective only for males. There were no significant associations between the neighborhood variables and nonuse of alcohol, and the neighborhood variables did not influence the asset/nonuse of alcohol associations. Conclusions: Youth assets appear to protect both genders from future alcohol use but
\end{abstract}

males may benefit even more from asset-building prevention programming. Youth alcohol use and alcohol nonuselasset associations may not be influenced by the neighborhood environment.

Keywords: Youth Tobacco Use; Youth Assets; Gender Analyses; Neighborhood Environment

\section{INTRODUCTION}

US data indicate that youth alcohol use began declining in 2001 from approximately $50 \%$ of surveyed youth to $39 \%$ in 2011 . Notably, from 1991 to 2001 the percentage of male youth reporting alcohol use was consistently greater compared to female youth. However, beginning in 2003 the percentage of alcohol use by male and female youth was similar and in two years (2003, 2009) the percentage of females reporting alcohol use was greater compared to males [1]. These data indicate that youth alcohol use remains a serious public health concern and that possible gender differences associated with alcohol use merit investigation.

There is increased interest in examining multiple promotive factors (assets) that may protect youth from participating in risky behaviors such as alcohol use [2-5]. For example, research has reported that assets such as family communication, school connectedness, maternal support, parental monitoring, decision making skills, life purpose, and peer role models are associated with delayed onset and reduced frequency of alcohol use [3, 6-10]. However, much of this research has focused on a limited number of assets that were typically individual or family-level assets, and employed cross-sectional rather than longitudinal study design methodology [3]. Therefore, 
the first goal of the present study is to prospectively assess associations between numerous assets and youth nonuse of alcohol across 5 waves of data collected annually over 4 years. The assets are conceptualized as influencing youth alcohol use at multiple levels (youth, family, and community) which is similar to the ecological approach to understanding health behavior [11].

In addition, very little research has investigated possible gender differences in regard to youth asset/alcohol use associations. A review of factors associated with youth alcohol use reported little evidence for gender differences [12]. However, a cross-sectional study found that adolescent females with the constructive use of time related to religion or the ability to make responsible choices assets were approximately 4 times less likely to initiate alcohol use compared to females without either asset. The assets were not significantly associated with nonuse of alcohol for the male adolescents [7]. A second goal of the current study is to prospectively examine youth gender differences in the associations between multiple assets and youth nonuse of alcohol.

The potential influence of neighborhood factors is also of interest in studies of youth outcomes [13]. One perspective for understanding how neighborhoods may influence behavior is social disorganization theory which was first posited by Shaw and McKay [14] and refined by Sampson and Groves [15] and others [e.g., 16-18] in research on delinquency and crime. The theory proposes that neighborhood structural factors and social processes such as socio-economic status, residential mobility, racial heterogeneity, family structure, collective efficacy, sense of community, and informal social control can influence youth behavior through multiple pathways. These neighborhood characteristics are typically assessed using census data or data collected from research participants. For example, research using census study participant data found that neighborhood-related stress and lower social cohesion were significantly related to youth alcohol use or perceived problems with youth alcohol use $[8,19]$. However, another study using similar methods reported that neighborhood disadvantage was not related to youth alcohol use [9].

Another approach to assessing neighborhood effects on behavior is to objectively observe and quantify the physical condition of neighborhoods. This approach, referred to as the Broken Windows (BW) theory, suggests that neighborhoods in poor condition (e.g., residences in disrepair, large amounts of trash and graffiti) are a signal that delinquency and crime are tolerated [20]. One of the few studies published in this area found that a measure of BW was associated with neighborhood gonorrhea rates and with off-site alcohol outlet density [21]. To our knowledge, there are no published studies investigating associations between the physical condition of the neighborhood and youth alcohol use. Therefore, the third goal of the current study is to prospectively investigate possible associations among neighborhood variables (neighborhood social processes as well as the physical condition of the neighborhood), assets, and youth nonuse of alcohol and determine if associations between assets and nonuse of alcohol vary due to the presence of neighborhood factors.

\section{METHODS}

\subsection{Sampling and Data Collection}

Census tracts in Oklahoma City were stratified by income and race/ethnicity using 2000 census data and then randomly selected with the goal of obtaining a racially/ ethnically and economically diverse community-based study population. Twenty census tracts were included in the study. Door-to-door canvassing within the selected census tracts was conducted to obtain the baseline sample of youth and parents. Inclusion criteria for the study were that the youth were 12 to 17 years of age; lived with a parent or guardian; spoke English or Spanish; possessed the cognitive functioning to respond to interviewer questions and complete the survey; and had no plans to move from the study area within the next two years. One youth and one parent from each consenting household participated in the study [22].

Data were collected from youth/parent pairs using Computer-Assisted Personal/Self-Interviewing procedures conducted in their homes by two-person interviewing teams. However, youth completed the risk behavior items themselves in private using computers equipped with wav sound files and headphones to minimize potential reading problems. Five waves of data were collected annually from the participants beginning with the baseline survey conducted in 2003/2004 and concluding in 2007/2008. A total of 1111 youth/parent pairs participated in the study with a response rate of $61 \%$ that was calculated using formulas and guidelines suggested by the American Association for Public Opinion Research [23]. The retention rate across all five waves (i.e., valid completed youth interview for all five waves) was $89 \%$ (986/1111).

\subsection{Measures}

Time constant demographic variables reported by the youth and included in the statistical modeling were age at baseline, race/ethnicity and family structure. Family structure was assessed at each interview. At baseline the response options were one- or two-parent household; at subsequent waves, the youth could respond "independent" if they had lived alone for at least 6 months. If a youth consistently reported one-parent household, the 
time constant family structure was coded as "one parent." Youth consistently reporting two-parent households were coded as "two parent." Youth who reported both one- and two-parent households over the 5 data collection periods or who reported "independent" before the age of 18 years were coded as "inconsistent". Parental education was reported by the parents and it was time-varying and lagged in the statistical modeling.

Youth Assets. Seventeen youth assets were assessed via multi-item constructs with established validity and reliability. Seven assets operated at the individual level, 4 at the family level, and 6 at the community level. The asset constructs were conceptualized and developed based on literature reviews, previous research, and psychometric testing [5,24,25]. Items representing each asset were summed and divided by the number of items to create a score ranging from 1 (almost never/strongly disagree) to 4 (almost always/strongly agree). The reliability of the asset constructs was adequate (Cronbach's alphas $>0.70$ for 11 assets, $>0.60$ and $\leq 0.70$ for four assets, and $\geq 0.55$ and $\leq 0.60$ for two assets).

A total asset score was computed by summing all 17 individual asset scores (range $=17$ to 68 ). The interartile range for the total asset score was approximately 8 and therefore a change of 4 points in the total asset score was deemed to be relevant. Therefore, when the odds ratio (OR) is interpreted for the total asset score, it compares the odds for youth that have a 4 point change in the total asset score in contrast to the 1-point change in the asset score that was used for the single asset analysis.

The assets were tested for multi-collinearity. The Pearson correlation coefficients among the 17 asset constructs ranged from 0.02 to 0.49 . Only $4 \%$ of the coefficients were between 0.40 and 0.49 and the majority $(69 \%)$ were between 0.10 and 0.29 . The results indicate that each asset is a distinct asset.

Neighborhood Condition. Neighborhood condition was assessed annually by trained raters who conducted windshield tours of each census tract objectively assess neighborhoods using the BW instrument [20,21]. The survey classifies neighborhoods according to the contion of the houses, and the amount of trash, graffiti, and abandoned cars. The BW survey score ranged from 0 (neighborhood in poorer condition) to 12 (neighborhood in better condition). The Spearman correlation coefficient for the test-retest reliability of the BW survey was 0.83 and the intraclass correlation was 0.80 . The BW score was analyzed as a categorical variable with 4 levels: 1 to $<7$ (poorest condition) versus 7 to $<9$ (poor condition) versus 9 to $<11$ (better condition) versus 11 to 12 (best condition).

Neighborhood Social Processes. Five neighborhood social process variables were assessed in the parent interviews. All of the variables were multi-item con- structs that were created by summing the responses to the items representing each construct and dividing by the number of items.

Neighborhood concerns related to crime and safety and to services were assessed with 5 items (Cronbach's alpha $=0.87$ ) such as "There is crime and violence in your neighborhood" [26,27].

Neighborhood concerns related to services was assessed with 4 items (Cronbach's alpha $=0.69$ ) such as, "There is poor police protection in your neighborhood" $[26,27]$. Possible responses for the neighborhood concern questions ranged from one (strongly agree) to four (strongly disagree).

Neighborhood support was assessed with 5 items (Cronbach's alpha $=0.77$ ) such as, "About how often do you and people in your neighborhood watch over each other's property?" [28]. Responses ranged from one (almost never) to four (almost always). The neighborhood concern and support variables were analyzed as categorical variables with 3 levels: 1 to $<2$ (low) versus 2 to $<3$ (middle) versus 3 to 4 (high).

Sense of community was assessed using 7 items (Cronbach's alpha $=0.84$ ) from the Psychological Sense of Community (PSOC) scale such as "People in this neighborhood get along with each other" [29]. Possible responses ranged from one (strongly disagree) to four (strongly agree).

Informal social control was assessed with 5 items (Cronbach's $=0.82$ ) such as, "How likely is it that your neighbors will become involved if children are skipping school and hanging out on the street corner?" [18]. Responses for the scale ranged from one (very unlikely) to four (very likely). PSOC and informal social control were analyzed as dichotomous variables: 1 to $<3$ (low) versus 3 to 4 (high).

A neighborhood environment composite score was also created by summing the neighborhood condition and social processes and dividing by the number of constructs (6). The score ranged from 1 to 4.

Non Use of Alcohol. Nonuse of alcohol was assessed by the item "During the past 30 days, did you drink any alcohol, such as beer, wine, or liquor, (Yes/No)?" The item was modified based on items used in the Youth Behavioral Risk Factor Surveillance Study and the Prevention Minimum Evaluation Data Set [1,30].

\subsection{Statistics}

Data were stratified by gender and analyzed longitudinally using marginal logistic regression analyses. All four demographic variables (youth age, race/ethnicity, family structure, parental education) were controlled for in all analyses with parental education analyzed as time-varying and lagged. A diagonal working covariance 
matrix was used as recommended by Pepe and Anderson when covariates vary over time [31].

Individual assets, asset score total, the six neighborhood variables, and the neighborhood composite score were analyzed as time-varying and lagged (e.g., asset wave 1 with nonuse of alcohol at wave 2). The total asset score evaluated the collective impact of the assets and then each asset was analyzed separately. The overall impact of the neighborhood variables was assessed with the neighborhood composite score and each neighborhood variable was also analyzed separately.

Interactions among the total asset score, assets, six neighborhood factors, neighborhood composite score, and the youth and parent demographic variables were analyzed. Each asset/outcome association was analyzed separately and with the neighborhood composite score to determine if the neighborhood influenced the relationship between the asset and nonuse of alcohol. Each neighborhood variable/nonuse of alcohol association was analyzed separately with the total asset score to determine if the assets influenced the relationship between the asset and nonuse of alcohol.

Gender interactions were evaluated using the full sample to determine if the asset and neighborhood variables and nonuse of alcohol relationships were significantly different between males and females. Final asset models for each gender were constructed beginning with the four demographic variables and all assets and neighborhood variables (or interactions) that were significant; only variables (or interactions) that were significant in the presence of the other significant variables remained in the model. Alpha was set at 0.05 for analyses of the relationship between nonuse of alcohol and the assets and neighborhood variables and possible gender interactions. Alpha was set at 0.005 for all other interactions to control type I error.

\section{RESULTS}

\subsection{Descriptive Data}

At baseline 1111 youth were interviewed. The analysis lagged the demographics, assets, and neighborhood variables at wave 1 with the alcohol outcome at wave 2 and then wave 2 with wave 3 , etc., resulting in four time points for data analysis. Over these 4 time points 1093 youth (574 females, 519 males) were in the analysis. For each time point the samples sizes for females were: 560 , 548, 547, and 548; and for males: 510, 501, 483, and 477. There were no missing data for youth age, gender, or race/ethnicity or family structure. At baseline there were no missing values for parental education. Parental education was missing 43 times in subsequent waves; in these cases parental education from a prior wave was carried forward.
Wave 1 descriptive statistics for the complete sample as well as by gender are presented in Table 1. There were no significant differences $(p>0.05)$ between females and males for these data. There was a significant interaction with alcohol use between gender and wave; the change in the percentage reporting alcohol use at baseline was significantly lower for males than females but then increased at a greater rate compared to females (Figure 1).

Table 2 shows wave 1 mean asset and neighborhood scores stratified by gender. Assets with higher mean scores (stronger assets) were cultural respect, educational aspirations for the future, and parental monitoring. Assets with lower mean scores (weaker assets) were community involvement, use of time (groups/sports), and use of time (religion).

\subsection{Relationship between Assets, Environmental Variables, and No Alcohol Use}

Females. Twelve assets as well as the total asset score were prospectively related with nonuse of alcohol (Table 3). None of the ORs were significantly larger when compared to the ORs from the analyses of the male data. The associations between assets and nonuse of alcohol changed little after controlling for the neighborhood composite score and associations between the total asset score and nonuse of alcohol also changed little after controlling for each neighborhood variable (data not shown). The final model analyses indicated that females with any one of 3 assets were significantly more likely to report nonuse of alcohol compared to females without any one of the 3 assets (Table 4).

Males. Sixteen assets as well as the total asset score were prospectively related with nonuse of alcohol (Table 3). The ORs for the total asset score and 3 of the significant asset/nonuse of alcohol associations were significantly larger than the same ORs from the female analyses. One interaction was identified. General selfconfidence was associated with higher odds of nonuse of alcohol only for youth whose parents both had less than a high school education $(\mathrm{OR}=2.49,95 \% \mathrm{CI}=1.46,4.26)$ or whose parents had at least a high school degree or some college $(\mathrm{OR}=1.40,95 \% \mathrm{CI}=1.02,1.93)$. The associations between assets and no alcohol use changed little after controlling for the neighborhood composite score and associations between the total asset score and nonuse of alcohol also changed little after controlling for each neighborhood variable (data not shown).

The final model analyses showed that male youth with any one of 4 assets were significantly more likely to report nonuse of alcohol use compared to males without 


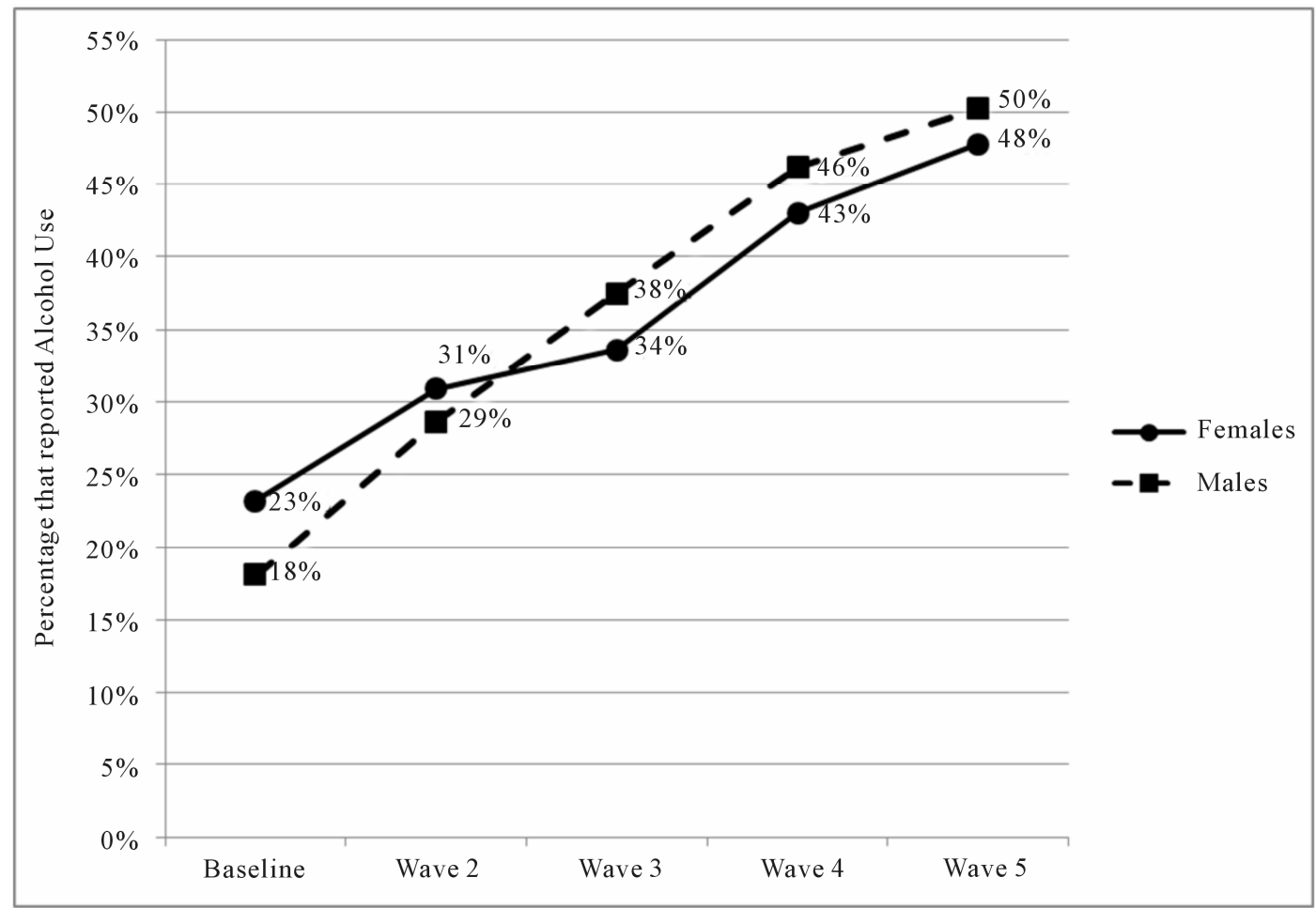

Figure 1. Percentage of female and male youth who reported drinking alcohol in past 30 days by study wave.

Table 1. Baseline demographic characteristics of the total sample, females, and males.

\begin{tabular}{|c|c|c|c|c|}
\hline & & $\begin{array}{c}\text { Total Sample } \\
(\mathrm{N}=1093)\end{array}$ & $\begin{array}{l}\text { Females } \\
(n=574)\end{array}$ & $\begin{array}{c}\text { Males } \\
(\mathrm{n}=\mathbf{5 1 9})\end{array}$ \\
\hline \multicolumn{2}{|c|}{ Demographic Characteristic } & n (\%) & n (\%) & n (\%) \\
\hline \multicolumn{2}{|c|}{ Age in years (mean, sd) } & $14.3(1.59)$ & $14.4(1.58)$ & $14.2(1.60)$ \\
\hline \multirow{4}{*}{ Race/Ethnicity } & Non-Hispanic Black & $257(23.5 \%)$ & $132(23.0 \%)$ & $125(24.1 \%)$ \\
\hline & Non-Hispanic White & $436(39.9 \%)$ & $228(39.7 \%)$ & $208(40.1 \%)$ \\
\hline & Hispanic & $302(27.6 \%)$ & $161(28.0 \%)$ & $141(27.2 \%)$ \\
\hline & Non-Hispanic Other & $98(9.0 \%)$ & $53(9.2 \%)$ & $45(8.7 \%)$ \\
\hline \multirow{3}{*}{ Parent Education } & Both $<$ HS & $176(16.1 \%)$ & $92(16.0 \%)$ & $84(16.2 \%)$ \\
\hline & One HS/No College & $612(56.0 \%)$ & $323(56.3 \%)$ & $289(55.7 \%)$ \\
\hline & At Least 1 College & $305(27.9 \%)$ & $159(27.7 \%)$ & $146(28.1 \%)$ \\
\hline \multirow{3}{*}{ Family Structure } & Two Parent & $630(57.6 \%)$ & $329(57.3 \%)$ & $301(58.0 \%)$ \\
\hline & One Parent & $235(21.5 \%)$ & $128(22.3 \%)$ & $107(20.6 \%)$ \\
\hline & Inconsistent & $228(20.9 \%)$ & $117(20.4 \%)$ & $111(21.4 \%)$ \\
\hline
\end{tabular}

any one of the assets. Interestingly, males with the use of time (groups/sports) asset were less likely to report nonuse of alcohol compared to males without the asset and males with the general self-confidence asset and who had at least one parent with a college degree were also less likely to report nonuse of alcohol compared to males with the asset (Table 4).

\section{DISCUSSION}

This longitudinal study investigated associations bet ween 17 youth assets, neighborhood environment, and nonuse of alcohol in a community-based random sample of racial/ethnically-diverse youth with the goal of exploring potential differences between females and males. 
Table 2. Wave one descriptive statistics for youth assets and neighborhood variables by gender.

\begin{tabular}{|c|c|c|c|c|}
\hline \multirow{2}{*}{ Variable } & \multicolumn{2}{|c|}{ Female } & \multicolumn{2}{|c|}{ Male } \\
\hline & $\mathbf{N}$ & Mean (sd) & $\mathbf{N}$ & Mean (sd) \\
\hline \multicolumn{5}{|l|}{ Assets } \\
\hline Total Asset Score & 560 & $52.89(5.63)$ & 510 & $52.10(6.00)$ \\
\hline \multicolumn{5}{|l|}{ Individual-level Assets } \\
\hline Responsible Choices & 560 & $3.50(0.52)$ & 510 & $3.36(0.60)$ \\
\hline Educational Aspiration & 560 & $3.61(0.48)$ & 510 & $3.53(0.56)$ \\
\hline General Aspirations for the future & 560 & $3.39(0.44)$ & 509 & $3.27(0.50)$ \\
\hline General Self Confidence & 560 & $3.23(0.48)$ & 510 & $3.28(0.49)$ \\
\hline Religiosity & 560 & $3.47(0.62)$ & 510 & $3.30(0.72)$ \\
\hline Cultural Respect & 560 & $3.60(0.44)$ & 510 & $3.50(0.47)$ \\
\hline Good Health Practices & 560 & $2.96(0.69)$ & 510 & $3.08(0.69)$ \\
\hline \multicolumn{5}{|l|}{ Family-level Assets } \\
\hline Family Communication & 560 & $2.92(0.71)$ & 510 & $2.77(0.67)$ \\
\hline Relationship with Mother & 559 & $3.36(0.63)$ & 503 & $3.51(0.52)$ \\
\hline Relationship with Father & 505 & $3.01(0.84)$ & 479 & $3.20(0.79)$ \\
\hline Parental Monitoring & 560 & $3.63(0.58)$ & 510 & $3.48(0.63)$ \\
\hline \multicolumn{5}{|l|}{ Community-level Assets } \\
\hline Parental Adult Roles & 560 & $3.24(0.47)$ & 510 & $3.18(0.51)$ \\
\hline Community Involvement & 560 & $2.18(0.80)$ & 510 & $1.97(0.72)$ \\
\hline Positive Peer Role Models & 560 & $3.01(0.67)$ & 510 & $2.93(0.65)$ \\
\hline Use of Time (Group/Sports) & 556 & $2.33(0.89)$ & 509 & $2.36(0.91)$ \\
\hline Use of Time (Religion) & 560 & $2.66(0.82)$ & 510 & $2.56(0.87)$ \\
\hline School Connectedness & 554 & $3.15(0.57)$ & 506 & $3.11(0.54)$ \\
\hline \multicolumn{5}{|l|}{ Neighborhood Variables } \\
\hline Neighborhood Composite Score & 560 & $2.75(0.48)$ & 510 & $2.76(0.48)$ \\
\hline \multicolumn{5}{|l|}{ Neighborhood Condition } \\
\hline \multicolumn{5}{|l|}{ Broken Windows } \\
\hline Low & 160 & $28.6 \%$ & 153 & $30.0 \%$ \\
\hline Middle-Low & 125 & $22.3 \%$ & 117 & $22.9 \%$ \\
\hline Middle-High & 155 & $27.7 \%$ & 123 & $24.1 \%$ \\
\hline High & 120 & $21.4 \%$ & 117 & $22.9 \%$ \\
\hline \multicolumn{5}{|l|}{ Neighborhood Social Processes } \\
\hline \multicolumn{5}{|l|}{ Neighborhood Concerns: Services } \\
\hline Low & 67 & $12.0 \%$ & 56 & $11.0 \%$ \\
\hline Middle & 142 & $25.4 \%$ & 123 & $24.1 \%$ \\
\hline High & 351 & $62.7 \%$ & 331 & $64.9 \%$ \\
\hline \multicolumn{5}{|c|}{ Neighborhood Concerns: Crime/Safety } \\
\hline Low & 118 & $21.3 \%$ & 93 & $18.6 \%$ \\
\hline Middle & 203 & $36.7 \%$ & 192 & $38.4 \%$ \\
\hline High & 232 & $42.0 \%$ & 215 & $43.0 \%$ \\
\hline \multicolumn{5}{|l|}{ Neighborhood Support } \\
\hline Low & 205 & $36.7 \%$ & 206 & $40.4 \%$ \\
\hline Middle & 276 & $49.4 \%$ & 234 & $45.9 \%$ \\
\hline High & 78 & $14.0 \%$ & 70 & $13.7 \%$ \\
\hline \multicolumn{5}{|l|}{ Sense of Community } \\
\hline Low/Middle & 158 & $28.3 \%$ & 154 & $30.5 \%$ \\
\hline High & 400 & $71.7 \%$ & 351 & $69.5 \%$ \\
\hline \multicolumn{5}{|l|}{ Informal Social Control } \\
\hline Low/Middle & 146 & $26.4 \%$ & 132 & $26.2 \%$ \\
\hline High & 406 & $73.6 \%$ & 371 & $73.8 \%$ \\
\hline
\end{tabular}


Table 3. Adjusted odds ratios for the assets and neighborhood variables on nonuse of alcohol by gender.

\begin{tabular}{|c|c|c|c|c|}
\hline \multirow{2}{*}{ Variable } & \multicolumn{2}{|c|}{ Female } & \multicolumn{2}{|c|}{ Male } \\
\hline & OR* $(95 \% \mathrm{CI})$ & P-value & $\mathrm{OR}^{*}(95 \% \mathrm{CI})$ & P-value \\
\hline \multicolumn{5}{|l|}{ Assets } \\
\hline Total Asset Score ${ }^{\dagger}$ (units $=4$ ) & $1.24(1.14,1.35)$ & $<0.0001$ & $1.39(1.27,1.52)$ & $<0.0001$ \\
\hline \multicolumn{5}{|l|}{ Individual-level Assets } \\
\hline Responsible Choices & $1.35(1.10,1.66)$ & 0.0041 & $1.83(1.48,2.25)$ & $<0.0001$ \\
\hline Educational Aspiration & $1.15(0.93,1.43)$ & 0.2002 & $1.40(1.14,1.72)$ & 0.0016 \\
\hline General Aspirations for the Future & $1.25(0.98,1.58)$ & 0.0720 & $1.66(1.29,2.12)$ & $<0.0001$ \\
\hline General Self Confidence & $1.12(0.89,1.40)$ & 0.3226 & Interaction & \\
\hline Religiosity & $1.50(1.23,1.83)$ & $<0.0001$ & $1.74(1.44,2.10)$ & $<0.0001$ \\
\hline Cultural Respect $^{\dagger}$ & $0.79(0.61,1.02)$ & 0.0735 & $1.23(0.95,1.59)$ & 0.1120 \\
\hline Good Health Practices & $1.31(1.13,1.52)$ & 0.0004 & $1.22(1.03,1.45)$ & 0.0229 \\
\hline \multicolumn{5}{|l|}{ Family-level Assets } \\
\hline Family Communication & $1.31(1.14,1.52)$ & 0.0002 & $1.62(1.34,1.95)$ & $<0.0001$ \\
\hline Relationship with Mother & $1.12(0.95,1.32)$ & 0.1960 & $1.47(1.16,1.87)$ & 0.0014 \\
\hline Relationship with Father & $1.20(1.03,1.39)$ & 0.0171 & $1.32(1.12,1.57)$ & 0.0012 \\
\hline Parental Monitoring $^{\dagger}$ & $1.60(1.35,1.90)$ & $<0.0001$ & $2.13(1.78,2.56)$ & $<0.0001$ \\
\hline \multicolumn{5}{|l|}{ Community-level Assets } \\
\hline Non Parental Adult Roles & $1.39(1.12,1.73)$ & 0.0029 & $1.60(1.26,2.04)$ & 0.0001 \\
\hline Community Involvement ${ }^{\dagger}$ & $1.23(1.07,1.40)$ & 0.0030 & $1.58(1.31,1.89)$ & $<0.0001$ \\
\hline Positive Peer Role Models ${ }^{\dagger}$ & $1.53(1.30,1.80)$ & $<0.0001$ & $2.02(1.68,2.44)$ & $<0.0001$ \\
\hline Use of Time (Group/Sports) & $1.24(1.09,1.41)$ & 0.0008 & $1.16(1.01,1.33)$ & 0.0322 \\
\hline Use of Time (Religion) & $1.24(1.09,1.40)$ & 0.0010 & $1.45(1.26,1.67)$ & $<0.0001$ \\
\hline School Connectedness & $1.34(1.10,1.63)$ & 0.0043 & $1.44(1.15,1.81)$ & 0.0014 \\
\hline \multicolumn{5}{|l|}{ Neighborhood Variables } \\
\hline Neighborhood Composite Score & $0.95(0.73,1.23)$ & 0.6996 & $0.92(0.69,1.21)$ & 0.5336 \\
\hline \multicolumn{5}{|l|}{ Neighborhood Condition } \\
\hline \multicolumn{5}{|l|}{ Broken Windows } \\
\hline Middle-Low vs Low & $0.92(0.70,1.21)$ & 0.5470 & $1.10(0.81,1.50)$ & 0.5532 \\
\hline Middle-High vs Low & $0.95(0.69,1.31)$ & 0.7574 & $0.87(0.62,1.23)$ & 0.4263 \\
\hline High vs Low & $0.89(0.61,1.31)$ & 0.5624 & $0.78(0.51,1.18)$ & 0.2436 \\
\hline \multicolumn{5}{|l|}{ Neighborhood Social Processes } \\
\hline \multicolumn{5}{|l|}{ Neighborhood Concerns: Services } \\
\hline Middle vs Low & $1.05(0.72,1.53)$ & 0.7855 & $0.92(0.61,1.39)$ & 0.7081 \\
\hline High vs Low & $1.12(0.79,1.58)$ & 0.5240 & $0.85(0.59,1.23)$ & 0.3830 \\
\hline \multicolumn{5}{|l|}{ Neighborhood Concerns: Crime/Safety } \\
\hline Middle vs Low & $0.92(0.70,1.22)$ & 0.5701 & $1.11(0.82,1.51)$ & 0.5066 \\
\hline High vs Low & $0.97(0.72,1.30)$ & 0.8404 & $1.23(0.89,1.70)$ & 0.2106 \\
\hline \multicolumn{5}{|l|}{ Neighborhood Support } \\
\hline Middle vs Low & $1.01(0.80,1.28)$ & 0.9088 & $1.08(0.85,1.37)$ & 0.5304 \\
\hline High vs Low & $1.09(0.76,1.58)$ & 0.6324 & $0.92(0.63,1.33)$ & 0.6484 \\
\hline \multicolumn{5}{|l|}{ Sense of Community } \\
\hline High vs Low/Middle & $0.83(0.65,1.05)$ & 0.1124 & $1.04(0.79,1.35)$ & 0.7885 \\
\hline \multicolumn{5}{|l|}{ Informal Social Control } \\
\hline High vs Low/Middle & $0.83(0.64,1.08)$ & 0.1667 & $1.03(0.78,1.35)$ & 0.8323 \\
\hline
\end{tabular}

*Adjusted for youth age and race/ethnicity, parental education, and family structure. ${ }^{\dagger}$ Significant difference $(p<0.05)$ between ORs for the female and male data as indicated by a significant interaction between the asset and gender in the adjusted model with all youth. Bold text indicates statistically significant $(p<$ 0.05 ) Odds Ratios. 
Table 4. Final models showing adjusted odds ratios for the assets on nonuse of alcohol by gender.

\begin{tabular}{|c|c|c|}
\hline & \multicolumn{2}{|c|}{ Females } \\
\hline & OR $^{*}(95 \% \mathrm{CI})$ & P-value \\
\hline \multicolumn{3}{|l|}{ Variable } \\
\hline Religiosity & $1.28(1.03,1.58)$ & 0.0227 \\
\hline Parental monitoring & $1.35(1.10,1.65)$ & 0.0034 \\
\hline \multirow[t]{2}{*}{ Positive peer role models } & $1.40(1.15,1.69)$ & 0.0006 \\
\hline & \multicolumn{2}{|l|}{ Males } \\
\hline \multicolumn{3}{|l|}{$\begin{array}{l}\text { General self-confidence } \\
\text { (Interaction) }\end{array}$} \\
\hline Both $<$ HS & $1.38(0.78,2.37)$ & 0.2713 \\
\hline $\begin{array}{l}\text { At least one parent HS } \\
\text { degree or some college }\end{array}$ & $0.82(0.56,1.22)$ & 0.3321 \\
\hline At least one parent college & $0.45(0.27,0.75)$ & 0.0021 \\
\hline Religiosity & $1.42(1.15,1.74)$ & 0.0010 \\
\hline Parental monitoring & $1.79(1.46,2.21)$ & $<0.0001$ \\
\hline Community involvement & $1.31(1.07,1.60)$ & 0.0091 \\
\hline Positive peer role models & $1.59(1.28,1.99)$ & $<0.0001$ \\
\hline Use of time (groups/sports) & $0.84(0.72,0.98)$ & 0.0296 \\
\hline
\end{tabular}

*Adjusted for youth age and race/ethnicity, parental education, family structure, and the other assets in the model. Bold text indicates statistically significant $(p<0.05)$ Odds Ratios.

Youth assets were categorized into one of three pathways of behavior change (individual, family, community) [11].

The results suggest there are numerous assets that may protect females (12 assets) and male (16 assets) adolescents from using alcohol [3,6-10]. Family and community level assets, with few exceptions, were protective from alcohol use for all of the youth. However, more individual level assets were protective from alcohol use for males. In addition, the total asset score and three assets (parental monitoring, community involvement, positive peer role models) were significantly more protective from alcohol use for males. These data suggest that male adolescents may benefit even more than females from prevention programming that focuses on asset building. The results also contribute to research suggesting gender differences in regard to asset/risk behavior associations $[7,8,32]$.

The final model analyses suggest that female and male youth also have assets in common that protect them from alcohol use (religiosity, parental monitoring, positive peer role models). Thus, prevention programming that focuses on both genders has some guidance regarding asset building that may benefit all youth. Positive associations between parental monitoring skills and positive peer role models and risk behavior avoidance including alcohol use have been previously evaluated $[3,7,8,33]$.
This study's longitudinal data, that included the use of multi-item psychometrically sound measures of parental monitoring and positive peer role models, are additional evidence for the importance of these assets.

Assets are conceptualized as protecting youth from engaging in risk behaviors. Interestingly, the general self-confidence asset for youth with at least one parent who had a college degree and the use of time (groups/ sports) asset were associated with increased odds for alcohol use for males. At least one other longitudinal study found a small but significant association between higher self-esteem and increased alcohol use [34]; and other research has reported that youth living in higherincome households are more likely to use alcohol [35, 36]. Other research has noted a link between participation in sports and increased alcohol use [37] and one study reported that youth who played team sports, as compared to individual sports, were more likely to use alcohol [38]. These results suggest that in specific situations certain assets may contribute to increased alcohol use.

Perhaps the most surprising result was the lack of significant associations between the neighborhood factors and alcohol use. Furthermore, the protective effects of assets from alcohol use changed little in the presence of the neighborhood factors. The study prospectively examined concepts of social disorganization theory (e.g., sense of community, informal social control; neighborhood support) as well as several variables that fit within the theory (e.g., neighborhood physical condition, neighborhood concerns related to crime, safety, and services) while controlling for other theory variables that are typically assessed using census data (e.g., socioeconomic status, family structure) and found that none of them were related to youth alcohol use. The results seem to suggest that social disorganization theory is a more robust explanatory model for crime and delinquency [ 15 , 16] than for youth alcohol use [9]. However, methodological differences between this study and research conducted in the crime and delinquency field are substantial and thus direct comparisons should be made with caution. For example, studies of social disorganization theory with crime and delinquency as the outcome typically include several thousand participants and account for macro-level factors such as immigration, homeownership, labor markets, and residential stability [e.g., 15,18]

In conclusion, risk behavior prevention programs that target youth alcohol use may be improved by strengthening specific assets identified in this study. Assetbased programming can focus on numerous assets at the family and community level that protect both female and male adolescents or narrow the focus to a few assets that appear to be most important for protecting one or both 
genders from alcohol use. The neighborhood environment, operationally defined as social processes as well as the physical condition of the neighborhood, was not associated with alcohol use in this community-based sample of racially/ethnically and economically diverse youth.

\section{ACKNOWLEDGEMENTS}

The Youth Asset Study was supported by funding from the Centers for Disease Control and Prevention (CDC) Grant Number 5 U01 DP000132, National Institutes of Health Grant Number 1R03DA 025265-01A1 and the Inasmuch Foundation. The contents of this publication are solely the responsibility of the authors and do not necessarily represent the official views of the CDC, NIH or Inasmuch Foundation.

\section{REFERENCES}

[1] Centers for Disease Control and Prevention (2012) Youth Risk Behavior Surveillance System (YRBSS). http://www.cdc.gov/HealthyYouth/yrbs/index.htm

[2] Jessor, R.J., Turbin, M.S. and Costa, F.M. (1998) Protective factors in adolescent health behavior. Journal of Personality and Social Psychology, 75, 788-800. doi:10.1037/0022-3514.75.3.788

[3] Fergus, S. and Zimmerman, M.A. (2005) Adolescent resilience: A framework for understanding healthy development in the face of risk. Annual Review of Public Health, 26, 399-419.

doi:10.1146/annurev.publhealth.26.021304.144357

[4] Oman, R.F., et al. (2004) The association between multiple youth assets and sexual behavior. American Journal of Health Promotion, 19, 12-18. doi:10.4278/0890-1171-19.1.12

[5] Oman, R.F., et al. (2010) Reliability and validity of the youth asset survey: An update. American Journal of Health Promotion, 25, e13-e24. doi:10.4278/ajhp.081009-QUAN-242

[6] Johnson, K., et al. (1996) Reducing alcohol and other drug use by strengthening community, family, and youth resiliency. Journal of Adolescent Research, 11, 36-67. doi: $10.1177 / 0743554896111004$

[7] Oman, R.F., et al. (2004) The potential protective effect of youth assets on adolescent alcohol and drug use. American Journal of Public Health, 94, 1425-1430. doi:10.2105/AJPH.94.8.1425

[8] Scheier, L.M., Botvin, G.J. and Miller, N.L. (2000) Life events, neighborhood stress, psychosocial functioning, and alcohol use among urban minority youth. Journal of Child \& Adolescent Substance Abuse, 9, 19-50. doi:10.1300/J029v09n01 02

[9] Brenner, A., Bauermeister, J. and Zimmerman, M. (2011) Neighborhood variation in adolescent alcohol use: Examination of socioecological and social disorganization theories. Journal of Studies on Alcohol and Drugs, 72, 651-659.

[10] Resnick, M.D., et al. (1997) Protecting adolescents from harm: Findings from the National Longitudinal Study on Adolescent Health. Journal of the American Medical Association, 278, 823-832. doi:10.1001/jama.1997.03550100049038

[11] McLeroy, K., et al. (1988) An ecological perspective on health promotion programs. Health Education Quarterly, 15, 351-377. doi:10.1177/109019818801500401

[12] Donovan, J.E. (2004) Adolescent alcohol initiation: A review of psychosocial risk factors. The Journal of Adolescent Health: Official Publication of the Society for Adolescent Medicine, 35, 529.e7-529.e18.

[13] Leventhal, T. and Brooks-Gunn, J. (2000) The neighborhoods they live in: The effects of neighborhood residence on child and adolescent outcomes. Psychological Bulletin, 126, 309-337. doi:10.1037/0033-2909.126.2.309

[14] Shaw, C.R. and McKay, H.D. (1942) Juvenile delinquency and urban areas. University of Chicago Press, Chicago.

[15] Sampson, R.J. and Groves, W.B. (1989) Community structure and crime: Testing social-disorganization theory. American Journal of Sociology, 94, 774-802. doi:10.1086/229068

[16] Bursik, R.J. (1988) Social disorganization and theories of crime and delinquency: Problems and prospects. Criminology, 26, 519-552. doi:10.1111/j.1745-9125.1988.tb00854.x

[17] Cantillon, D., Davidson II, W.S. and Schweitzer, J.H. (2003) Measuring community social organization: Sense of community as a mediator in social disorganization theory. Journal of Criminal Justice, 31, 321-339. doi:10.1016/S0047-2352(03)00026-6

[18] Sampson, R., Raudenbush, S. and Earls, F. (1997) Neighborhoods and violent crime: A multilevel study of collective efficacy. Science, 277, 918-924. doi:10.1126/science.277.5328.918

[19] Duncan, S., Duncan, T. and Strycker, L. (2002) A multilevel analysis of neighborhood context and youth alcohol and drug problems. Prevention Science, 3, 125-133. doi:10.1023/A:1015483317310

[20] Wilson, J. and Kelling, G. (1982) The police and neighborhood safety: Broken windows. The Atlantic Monthly, 127, 29-38.

[21] Cohen, D., et al. (2000) "Broken Windows" and the risk of gonorrhea. American Journal of Public Health, 90, 230-236. doi:10.2105/AJPH.90.2.230

[22] Oman, R.F., et al. (2009) Methodological considerations in a community-based longitudinal study. American Journal of Health Behavior, 33, 58-68. doi:10.5993/AJHB.33.1.6

[23] The American Association for Public Opinion Research (2004) Standard definitions: Final dispositions of case codes and outcome rates for surveys. 3rd Edition, The American Association for Public Opinion Research (AAPOR), Lenexa.

[24] Oman, R.F., et al. (2002) Reliability and validity of the youth asset survey (YAS). Journal of Adolescent Health, 31, 247-255. doi:10.1016/S1054-139X(02)00363-4

[25] Kegler, M., et al. (2003) An asset-based youth development model for preventing teen pregnancy: Illustrations 
from the HEART of OKC project. Health Education, 103, 131-144. doi:10.1108/09654280310472351

[26] Aronson, R. and O’Campo, P. (1997) Neighborhood transformation: A report on neighborhood changes in physical, social, political and economic conditions between 1993 and 1997 in the Baltimore City Healthy Start Target Areas and Control Area. Healthy Start Policy Office, Baltimore City, 1-45.

[27] Kegler, M.C., et al. (2005) Relationships among youth assets and neighborhood and community resources. Health Education and Behavior, 32, 380-397. doi:10.1177/1090198104272334

[28] Buka, S.L., et al. (2003) Neighborhood support and the birth weight of urban infants. American Journal of Epidemiology, 157, 1-8. doi:10.1093/aje/kwf170

[29] McMillan, D. and Chavis, D. (1986) Sense of community: A definition and theory. Journal of Community Psychology, 14, 6-23. doi:10.1002/1520-6629(198601)14:1<6::AID-JCOP2290 140103>3.0.CO;2-I

[30] Card, J., et al. (1999) Prevention Minimum Evaluation Data Set (PMEDS). 3rd Edition, Program Archive on Sexuality, Health and Adolescence (PASHA), Los Altos.

[31] Pepe, M. and Anderson, G. (1994) A cautionary note on inference for marginal regression models with longitudinal data and general correlated response data. Communication in Statistics-Simulation and Computation, 23, 939951. doi:10.1080/03610919408813210
[32] Mueller, T., et al. (2010) Youth assets and sexual risk behavior: Differences between male and female adolescents. Health Education and Behavior, 37, 343-356. doi:10.1177/1090198109344689

[33] DiClemente, R.J., et al. (2001) Parental monitoring: Association with adolescents' risk behaviors. Pediatrics, 107, 1363-1368. doi:10.1542/peds.107.6.1363

[34] Scheier, L.M., et al. (2000) Dynamic growth models of self-esteem and adolescent alcohol use. The Journal of Early Adolescence, 20, 178-209. doi: $10.1177 / 0272431600020002004$

[35] Blum, R.W., et al. (2000) The effects of race/ethnicity, income, and family structure on adolescent risk behaviors. American Journal of Public Health, 90, 1879-1884. doi:10.2105/AJPH.90.12.1879

[36] Oman, R.F., et al. (2002) An adolescent age group approach to examining youth risk behaviors. American Journal of Health Promotion, 16, 167-176. doi:10.4278/0890-1171-16.3.167

[37] Rainey, C.J., et al. (1996) Patterns of tobacco and alcohol use among sedentary, exercising, nonathletic, and athletic youth. Journal of School Health, 66, 27-32. doi:10.1111/j.1746-1561.1996.tb06254.x

[38] Peretti-Watel, P., et al. (2003) Sporting activity and drug use: Alcohol, cigarette and cannabis use among elite student athletes. Addiction, 98, 1249-1256. doi:10.1046/j.1360-0443.2003.00490.x 